\title{
PRECEDENTES JUDICIAIS À BRASILEIRA E O PÓS-POSITIVISMO: ANÁLISE DWORKIANA NA ATUAL FORMAÇÃO PRECEDENTALISTA
}

\author{
BRAZILIANS JUDICIAL PRECEDENTS AND THE POST-POSITIVIST: A DWORKIAN \\ ANALYSIS OF THE CURRENT PRECEDENTALIST FORMATION
}

Raissa Holanda Ramos ${ }^{1}$

Aceito em 10/04/2021

\author{
Ricardo Tinoco de Góes ${ }^{2}$
}

\section{RESUMO}

O artigo examina as bases hermenêuticas do que está no cerne do Código de Processo Civil brasileiro: os precedentes judiciais incorporados pela civil law oriundos docommon law. Observa-se a necessidade de evidenciar a inadequação dos precedentes judiciais à teoria clássica do ordenamento, pois os precedentes resistem ao positivismo normativista e ao formalismo. O objetivo é trazer à luz a forçosa redução na estrutura precedentalista, de modo a harmonizá-la, a todo custo, à forma de um dispositivo legal. Sob a égide de que precedente não deve ser estudado e aplicado como norma geral e abstrata, é preciso evidenciar que existe um conjunto de elementos a serem balizados na estruturação da força hermenêutica a circundar o precedente judicial. Ainda, é importante a interligação da hermenêutica em que não existe separação entre interpretar e aplicar, na contramão do que propõe a doutrina contemporânea. Para complementar, optou-se pelo referencial teórico do Direito como integridadede Ronald Dworkin, firmando uma pesquisa com emprego de abordagem qualitativa e método hipotético-dedutivo e dialético. Conclui-se que a integridade exige que os juízes construam seus argumentos integrados ao conjunto do Direito, sedimentando uma garantia contra arbitrariedades e efetivando os freios.

Palavras-chave: Precedentes Judiciais. Pós-positivismo. Ronald Dworkin. Integridade.

\section{ABSTRACT}

The article examines the hermeneutic bases of what is at the heart of the Brazilian Code of Civil Procedure: the judicial precedents incorporated by civil law from common law. There is a need to highlight the inadequacy of judicial precedents to the classical theory of ordering, as precedents resist normativist positivism and formalism. The objective is to bring to light the forced reduction in the precedentalist structure, in order to harmonize it, at all costs, in the form of a legal device. Under the aegis that precedent should not be studied and applied as a general and abstract norm, it is necessary to show that there is a set of elements to be guided in the structuring of the hermeneutic force surrounding the precedent. Still, the interconnection of hermeneutics is important, in which there is no separation between interpreting and applying, contrary to contemporary doctrine. In addition, the theoretical framework of law was chosen as the integrity of Ronald Dworkin, establishing a research using a qualitative approach and a hypothetical-deductive and dialectical method. It is concluded that integrity requires that judges build their arguments integrated with the set of Law, consolidating a guarantee against arbitrariness and putting the brakes on.

\footnotetext{
${ }^{1}$ Mestranda em Direito Constitucional pela Universidade Federal do Rio Grande do Norte (UFRN). Especialista em Direito Constitucional pela Faculdade Damásio/SP. Especialista em Direito Processual pela Pontifícia Universidade Católica de Minas Gerais (PUC/MG). Bolsista-pesquisadora da FAPERN/SEAD. Natal-RN-Brasil.

${ }^{2}$ Doutor em Filosofia do Direito pela Pontifícia Universidade Católica de São Paulo. Professor Adjunto da Universidade Federal do Rio Grande do Norte. Natal-RN-Brasil.
} 
Keywords: Judicial precedents. Post positivism. Ronald Dworkin. Integrity.

\section{INTRODUÇ̃̃o}

Os precedentes judiciais não são um instituto desconhecido do Direito brasileiro. Há anos os juristas tupiniquins buscam nas teorias estrangeiras uma resposta para os diversos desafios perpetuados no Poder Judiciário, sobretudo pelo aumento substancial de processos judiciais ativos e que exigem uma mudança no funcionamento da máquina judicial.

Nesse sentido, a teoria precedentalista peculiar ao sistema common law fora albergada pelo Direito pátrio. Com ares de formalidade, essa incorporação ocorreu pelo Código de Processo Civil de 2015 (CPC/15), especificamente ao prever nos artigos 926 e seguintes a necessidade de um sistema coeso, harmônico e íntegro.

Desta feita, resta evidente a influência de Ronald Dworkin no trabalho que conecta precedentes judiciais à seara filosófica do Direito e a sua importância para formular o novo modelo de decisão judicial a ser analisado.

Logo, diante da absorção por iniciativa legal de uma teoria pretensamente oposta ao positivismo jurídico e ao formalismo da norma, o objetivo do presente estudo será a identificação dessa incompatibilidade, a peculiaridade precedentalista do caso brasileiro na construção do direito jurisprudencial pátrio, a partir do norte teórico dworkiano, o qual prioriza por ler o direito sob a ótica da integridade.

\section{PRECEDENTES JUDICIAIS À BRASILEIRA: A (IN) COMPATIBILIDADE COM O POSITIVISMO JURÍDICO}

O sistema jurídico tradicional brasileiro preleciona pelo protagonismo da lei em albergar direitos e nortear a estruturação do Direito e do Estado. Diante de um ordenamento normativo hierarquizado e vertical, pautado no formalismo e rigor das leis, é natural tentar ajustar os institutos jurídicos estrangeiros ao modo brasileiro de "fazer Direito".

A bem da verdade, é sabido que o positivismo jurídico entende como justo aquilo que é comandado, exatamente pelo fato de sê-lo, nas palavras de Norberto Bobbio (2016, p. 58), tomando por consequência da validade à justiça da norma. A previsão legal só será justa se for validamente prevista, em distância ao conceito de moral. Ou seja, não existiria critério de justiça para além da moldura de uma lei positivada, sendo este ideal de justeza nada mais do que uma nuance subjetiva e atrelada à ética, desdobramento distinto do que deve importar, a saber: a objetividade de um comando normativo.

De fato, não é intenção do presente estudo esvaziar a importância do positivismo jurídico: esse representa uma das mais sólidas entre as conhecidas teorias do direito, inclusive é a que se sobressai no ensino jurídico no país (DIMOULIS, 2011, p. 216-217). Entretanto, fora em nome da segurança jurídica ofertada por esta linha do direito que a justiça - enquanto decisão equânime, digna - restou sacrificada em alguns momentos marcantes da história.

Em nome da lei, da previsibilidade das decisões e da justiça atrelada ao mero formalismo normativo, eis que crimes contra a humanidade foram cometidos tendo sido legitimados pelo Direito. Simbolicamente, o afastamento histórico do positivismo jurídico enquanto método preponderante e central ocorreu com a sucessão de crimes inenarráveis empreendidos ao longo da Segunda Guerra Mundial que culminaram no julgamento presenciado no Tribunal de Nuremberg ${ }^{3}$.

${ }^{3}$ Para aprofundar no tema, consultar o artigo científico de Moreira e Silva (2016). 


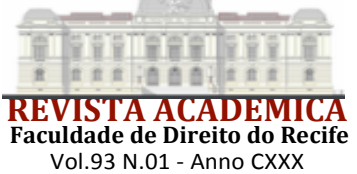

Desta feita, dispensa-se esforço teórico ao asseverar que não existe ordenamento jurídico ao redor do globo capaz de tutelar atrocidades e o extermínio de uma parcela considerável da raça humana. Com isso, fortaleceu-se o movimento de aproximação do Direito com a moral, reconhecido e denominado como o pós-positivismo.

Ainda assim, ao menos no Brasil, inegavelmente, o paradigma jurídico prevalecente dá-se sob as bases do positivismo legalista, apoiado no exame de textos legislativos e restringindo o Direito ao que é posto na lei. Mesmo com a transição para o pós-positivismo, os institutos do Direito brasileiro reiteradamente não encontram outro caminho senão o estritamente normativo. Diante disso, no cenário do positivismo brasileiro, não há distinção do texto com a norma jurídica e, por consequência, com o contexto de sua aplicação (CRUZ, 2008, p. 2).

Do mesmo modo, entende-se que o positivismo jurídico não é resumido à mera aplicação da literalidade da lei, inclusive porque fora uma norma democraticamente legitimada (STRECK, 2010 , p. 15). Isto, pois, ainda que diante de uma norma geral e abstrata com lacunas - sociais, jurídicas, econômicas -, deve-se levar em consideração que aquela fora produto da confluência de nichos partidários parlamentaristas, respeitando o pluralismo político e, sob algum viés, a representatividade popular. Ou seja, a constitucionalidade deve ser pautada como sua premissa inicial.

Nessa perspectiva, a crítica ao positivismo jurídico é tão necessária quanto atual, haja vista o objeto ora em análise: os precedentes judiciais à brasileira, assim denominados por terem sido incorporados pela mera previsão legal. Na verdade, essa teoria é compreendida enquanto refratária ao positivismo, ao formalismo, à unidade hierarquizada e a uma coerência promovida por critérios de solução de antinomias (LOPES FILHO, 2017, p. 157).

Além disso, registre-se que perseguir o mesmo trilho das normas gerais com os precedentes seria equipara-los, a despeito do nascedouro daquelas, não encontrando, necessariamente, assento constitucional - divorciando-se de qualquer esfera de competência outorgada pela Carta Magna.

De forma simplificada, pretendem o legislador e juristas apoiadores, transformar o Direito pátrio em um sistema de precedentes e teses, construindo-os como normas gerais e abstratas. Aqui, os termos gerais e abstratas não devem ser usados indiscriminadamente, pois gerais são as normas universais em relação aos destinatários, endereçadas a uma classe de pessoas, ao passo que abstratas regulam uma ação-tipo, universais em relação à ação (BOBBIO, 2016, p. 178).

Em verdade, a norma somente adquire o seu significado consoante a individualização conferida pelo intérprete no momento da aplicação ao caso concreto, porém difere da forma de empregar os precedentes judiciais que não se encaixam à casuística como as previsões normativas.

Os precedentes não são normas generalistas oriundos de um preceito individual criados pela primeira decisão cronologicamente prolatada, muito menos um caráter a ser assumido pela sentença quando da prolação de uma decisão judicial apta a criar uma norma geral. Aquele está para além da força de sua obrigatoriedade e de uma pretensão subjetiva, ou particular, em revestilo de norma geral. Com isso, os precedentes judiciais brasileiros não podem ser encarados sob a ótima da simplicidade da sua incorporação. A alteração normativa não deve ser reduzida a um mero primeiro passo (PEIXOTO, 2019, p. 139), haja vista ser esse, por si só, um problema na adoção precedentalista.

Ora, consoante é sabido, até o atual momento os países de origem alicerçada na common law resguardam ressalvas substanciais sobre a teoria em comento. Logo, não há uma pacificação absoluta sequer quanto à conceituação precedentalista em si, nada obstante ser a base do direito estudado, aplicado e laborado nas vias jurídicas americanas e inglesas - para citar os principais ordenamentos. 
A despeito disso, observa-se que os precedentes judiciais, ao aportarem na realidade pátria, objetivaram sobretudo resolver um problema quantitativo, além de combater a morosidade judicial, não raramente secundarizando a qualidade das decisões.

Portanto, como se pretende incorporar uma teoria centenária própria do direito estrangeiro a um sistema judicial organicamente distinto pela mera previsão legal? A que medida os precedentes judiciais deverão ser compreendidos e aplicados sem alterações na Constituição Federal para salvaguardar esse instituto?

Para além da normatividade, da hipervalorização e subserviência à incorporação legalista de uma cultura secular, apresenta-se aqui um viés contramajoritário. Defende-se que não há positivação da legitimação a ser pretensamente conferida aos Tribunais Superiores para elaborar teses gerais e abstratas, com efeito vinculatório. Esta é, pois, a função da doutrina: analisar criticamente o esforço de se produzir precedentes à brasileira pela via legislativa.

Afinal, resta inequívoco e democraticamente nocivo, o esvaziamento desta normatividade constitucional, diante da predileção por legitimar e tornar o direito precedentalista protagonista do cenário jurídico, cuja vinculação ${ }^{4}$ ainda está em processo de amadurecimento doutrinário.

Porém, não deveria ser passível de melhor diálogo a autorização legal concedida às Cortes Superiores para a produção de teses, transformando os juízes de primeiro em bouche de losprécédents, em rasa substituição aobouche de laloi? É razoável conferir espaço para o operador do direito nacional se adaptar à aplicação correta dos precedentes? Sem pretensões de tangenciar um maniqueísmo, mas a quem caberá a competência de ditar o que é certo?

Os tribunais não são órgãos legislativos e criadores de normas jurídicas gerais. Não por outra razão, as funções tipicamente legislativas e executivas são apartadas e pertencentes a entes distintos, autônomos.

A mudança substancial promovida pela adoção legalista de todo um sistema, não fora valorada pelo legislador no tocante à forma de tratamentos dos precedentes pelos próprios juízes brasileiros, cuja independência profissional passa a ser alvo. Com efeito, não faz parte da formação do magistrado ser tolhido em sua liberdade interpretativa a partir das decisões dos tribunais superiores.

É utópico prelecionar por uma teoria brasileira de precedentes, distante da influência anglo-saxã ou norte-americana, com a pretendida adaptação à realidade pátria, pois não será a formação de novos magistrados, tampouco a fugaz aprovação em lei infraconstitucional que serão suficientes para toda essa reconstrução. Esse é o retrato de uma típica importação acrítica do elemento central do common Law (STRECK, 2019, p. 15). Diga-se de passagem, a incorporação formalmente promovida pela previsão do Código de Processo Civil de 2015 fomenta a discussão doutrinária sobre a existência ou não de uma espécie de commonlização do direito, sem nenhum exagero retórico.

Noutro giro, a doutrina de Ronald Dworkin encontra guarida no presente trabalho pelo seu posicionamento contrário ao positivismo jurídico aplicado indistintamente a todos os casos, inclusive àqueles que integram a lacuna propiciada pelo texto aberto do direito (BAHIA, 2019, p. 119).

Para Dworkin, essa previsão geral e abstrata das normas positivas pode até funcionar para os casos repetitivos e habituais, contudo, para os "hard cases" ou "casos difíceis", tende a falhar. Entende o jurista que as proposições legais não são apenas descrições da história legal, mas são interpretativas (DWORKIN, 2002, p. 528).

As críticas de Dworkin são direcionadas principalmente à construção da decisão judicial, por consequência, do próprio precedente. Para o jurista, os magistrados não podem tecer vereditos com base em regras, pois o Direito não pode ser concebido como um sistema

\footnotetext{
${ }^{4}$ Para entender a vinculação que se pretende conferir aos precedentes judiciais, observa-se o seu amplo alcance para o "além-muros" do Direito: uma vinculação social, política, moral ou institucional, consoante é encontrado em Legale (2016, p. 828).
}

RAMOS, Raissa Holanda; DE GÓES, Ricardo Tinoco. PRECEDENTES JUDICIAIS À BRASILEIRA E O PÓS-POSITIVISMO: ANÁLISE DWORKIANA NA ATUAL FORMAÇÃO PRECEDENTALISTA. Revista Acadêmica da Faculdade de Direito do Recif - ISSN: 2448-2307, v. 93, n.1, p.338-349 Ab 
exclusivamente composto por elas, mas sim igualmente por princípios. O mundo vivido e a história precisam ser entendidos como influências às deliberações dos juízes (SAAVEDRA, 2006, p. 70), em concordância com o pós-positivismo pretendido.

Trazendo para a conjuntura brasileira, o Código em baila é posto como um instrumento na transição do positivismo, defensor da supremacia legal, para um viés pós-positivista (LUIZ, 2018, p. 309) inspirado em Ronald Dworkin. Entretanto, deve-se registrar a fragilidade dessa pretensão.

Há uma equivocada caracterização do positivismo como apenas exegético, com uma lei taxativa em si. O próprio positivismo se reformulou, reconhecendo a impossibilidade de existir previsão normativa para todas as hipóteses casuísticas: interpretações pelo aplicador são necessárias. Ao seu turno, o pós-positivismo não é um sistema repleto de conceitos vagos e arquétipos principiológicos (LUIZ, 2018, p. 310).

$\mathrm{Na}$ tentativa de se afastar do antigo $\mathrm{CPC} / 73$, no qual o juiz presidia o processo, em termos rígidos, o CPC/15 trouxe sinais de crise, mesmo albergando um magistrado em cooperação com as partes, e os litigantes não mais sujeitos processuais, mas, sim, atores. A legislação se propôs a abarcar diferentes teorias.

$\mathrm{Na}$ verdade, não há razão para afirmar, de pronto, que o $\mathrm{CPC} / 15$ ultrapassou o positivismo. Em absoluto, esse não é um código pós-positivista, dado que o modelo positivo ainda é hegemônico, consoante reconhecido anteriormente.

Sem dúvidas, no que tange aos precedentes judiciais, existe uma mixagem teórica quanto à forma da sua incorporação, o modo como realmente esses são construídos no direito tradicionalmente jurisprudencial e o caminho de aplicação galgado pelo direito brasileiro. Com essa miríade de orientações, entende-se não ser possível que a novel legislação possa delimitar a abrangência precedentalista.

Assim, a importação desta teoria pela simples via legalista, conflita com o próprio ordenamento jurídico brasileiro. Não por outra razão, a sua constitucionalidade inclusive é questionada e, diga-se de passagem, é notória a violação aos paradigmas constitucionais. Uma nova e complexa ordem jurídica fora forçosamente implementada por uma lei infraconstitucional.

Há quem observe aqui um traço cultural brasileiro, em adaptar os institutos estrangeiros às previsões legislativas particulares do direito pátrio, com a formação de um sistema próprio de precedentes, com todas as particularidades nativas. Entretanto, mesmo que se sustente pela legitimidade que cada país possui para construir, à sua maneira, o direito jurisprudencial, que o convém aos fenômenos sociais vividos, não se pode corroborar com esta pretensão (LUIZ, 2018, p. 314).

Como será benéfico ao direito brasileiro possibilitar a formação de teses jurídicas nos mesmos moldes legislativos de generalidade e abstração? Como permitir que um enunciado precedentalista já nasça com a natureza impositiva, vinculante a todas as decisões em âmbito nacional que coadunem com o dispositivo?

Pois bem. Configura-se errôneo seguir esta linha de raciocínio, haja vista a empreitada brasileira de albergar a teoria precedentalista, sob o fundamento justamente em uma tentativa de buscar formas inovadoras para os problemas antigos da praxe judicial brasileira. A aplicação de textos jurídicos gerais e abstratos mantém a mesma lógica utilizada, nada obstante a tendenciosa mudança na titularidade da responsabilidade e na origem dos textos: antes o Legislativo, agora o Poder Judiciário.

Com efeito, a incorporação ope legis dos precedentes judiciais fez com que fosse conferida ênfase aos aspectos formais. O Tribunal Superior prolator da decisão, ou o tipo de procedimento a partir do qual aquela fora formulada, passou a ter maior valia do que o mérito propriamente. 


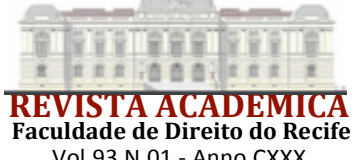

Vol.93 N.01 - Anno CXXX

Por outro lado, instaurou-se outra problemática. Uma vez que a estrutura formal encontrou o protagonismo, com os precedentes judiciais reduzidos a uma norma com formulação hermética, restou por mitigado o espaço para avaliar seu conteúdo, coerência e integridade.

Então, se ocorrer uma situação fática determinada, um certo precedente em específico será aplicado, em notória violação à cultura precedentalista em si. A sério, os precedentes não nascem como tal, mas são transformados em um à medida em que há o amadurecimento das discussões a respeito das matérias atinentes a esses.

Assim, esta incorporação precedentalista deu-se a partir de uma facilidade observada pelo legislador em simplificar os precedentes judiciais à previsão positivista. Há de se registrar que os precedentes não podem ser organizados pela mesma estrutura sistemática das normas legislativas. De fato, constituem um sistema próprio, não estruturado em pirâmide, mas em rede, cujas relações dispensam o formalismo das leis, constituídos pela razão oriunda da integridade, coerência e justificação das decisões anteriores (LOPES FILHO, 2017, p. 162).

Dessarte, há de se registrar a evidente inadequação dos precedentes judiciais à teoria clássica do ordenamento jurídico brasileiro, pautada no positivismo jurídico e a previsibilidade garantida pelas leis, oriunda da incompatibilidade daqueles aos elementos que lhes são característicos.

Entretanto, o esforço em estabelecer os precedentes judiciais diante da previsão legal está alicerçada na conveniência de situa-los no status quo do ordenamento jurídico brasileiro, no qual existe uma aposta máxima, um fetiche pela lei, como se essa abrangesse todo o conteúdo substancial, objetificado (STRECK, 2013, p. 26).

De certo, eis que houve a predileção por reduzir os precedentes judiciais, convencionalmente, a uma estrutura formal já reconhecida dentro da ótica positivista, do que realmente entender e discutir a cultura precedentalista. Isso não ocorreu mormente pelo ledo engano do legislador. Da mesma forma, não o fazem os juristas que assim pretendem reduzir os precedentes judiciais à uma previsão normativa simplória.

Portanto, pretendeu-se evidenciar que a formação dos precedentes judiciais nos moldes do direito brasileiro, há de ocorrer por outra formação sistemática e não pela simplificada previsão positiva. Mesmo porque, esta insistência do direito brasileiro em reiteradamente pautar seus institutos através do formalismo e objetividade do positivismo jurídico deveria ter sido superado pela mudança de paradigma, no qual o ordenamento jurídico há de ser interpretado e aplicado em concomitância, sem separação destas atividades.

\section{O SISTEMA PRECEDENTALISTA BRASILEIRO PELA PERSPECTIVA DE RONALD DWORKIN}

Conforme analisado, é sabida, neste trabalho com foco no ordenamento jurídico brasileiro, a necessidade de construir um novo sistema jurídico a fim de acompanhar a inovação dos precedentes judiciais. Como visto, a teoria clássica do positivismo jurídico do ordenamento acumula uma certa incompatibilidade com a teoria precedentalista ora analisada.

Por conseguinte, o esforço doutrinário está em entender a previsão normativa e a formação desta nova ordem jurídica a partir dos estudos de Ronald Dworkin, para quem o Direito não é um sistema fechado, haja vista a sua capilarização pelo ingresso de valores morais nele. O próprio precedente assim é: construído para adentrar ao tecido social, político e moral das nuances do sistema.

$\mathrm{Na}$ verdade, um parêntesis merece ser pontuado. Dessarte, transpassando o viés jurídiconormativo, nota-se a necessária preocupação com a construção dos precedentes judiciais diante da ausência de ocupação política no espaço público, fomentado pela Constituição Federal de 1988, a qual deveria limitar outros poderes e incrementar a representatividade social. 
Diga-se de passagem, é questionável a afirmação de Dworkin ao expressar um pressuposto de que nenhum grupo social possuiria mais capacidade moral de argumentação para decidir do que os juízes (DWORKIN, 2010, p. 128). Há de se perceber que aos magistrados não fora conferida uma espécie de conhecimento hercúleo. Inclusive, ao juiz deve ser incentivado perceber como a moral e a tradição histórica influenciam em seu critério decisório, sem discricionariedade. Essa é uma perspectiva exposta pelo próprio Dworkin, para quem o magistrado não possui uma livre escolha para resolver os hard cases (STRECK, 2009, p. 69).

À vista disso, o desafio conferido ao magistrado não deve ser de ignorar a norma positiva, pois essa ainda constitui a forma mais tradicional de organizar um sistema jurídico de tradição na civil law. Ao juiz é dado reconhecer o direito como uma criação que já fora fundada por leis, mas, igualmente, precisa ser influenciado por decisões que o próprio Poder Judiciário proferiu no passado (HORTA; NUNES; PEDRON, 2017, p. 327).

Essas decisões não podem e nem devem se perder no tempo. Os precedentes judiciais hão de garantir padrões decisórios, influenciando os atos seguintes. Entretanto, esses precedentes refutam a ideia de construção em si de normas gerais e abstratas, uma vez nociva à democracia e um estímulo ao juiz legiferante. Mesmo que seja recorrente asseverar que essa forma seria um aval ao engessamento do Poder Judiciário, ainda mais pelo caráter vinculante peculiar aos precedentes judiciais brasileiros.

Não por outra razão, defende-se que um dos elementos cruciais para a produção precedentalista é a própria discussão, pois não há propriedade ou titularidade das ideias. Essas precisam ser expostas aos que serão afetados, auxiliando ao magistrado em uma construção discursiva, democrática, quiçá habermasiana ${ }^{5}$. Assim, dispensando-se uma espécie de autoritarismo constitucional, haja vista a Constituição Federal servir para estruturar o Estado, seus entes, e não o povo.

Ao decidir o caso, o magistrado deve se colocar como cooperador no esforço em vislumbrar quais os direitos e deveres que os litigantes possuem, em diálogo com as partes, levando em consideração as decisões judiciais pretéritas, convenções, tradições, práticas sociais (HORTA; NUNES; PEDRON, 2017, p. 327).

Ao contrário do que poderá ser argumentado e da experiência que a praxe jurídica tende a impor, o juiz não se encontra em uma colocação privilegiada na pirâmide normativa, gerando problema na unidade do sistema jurídico. Acomodá-lo em posição horizontalizada no cerne do processo auxilia que a decisão prolatada seja a mais assertiva possível.

De fato, ao magistrado há de ser fomentado o desenvolvimento de capacidades pessoais para além da substancial utopia dworkiana de um juiz Hércules, detentor de todo o conhecimento e isolado em seu saber exclusivo. De sua vez, o "juiz-real" deve estar em sintonia com as convicções comunitárias, de modo a conferir legitimidade para as decisões judiciais construídas sob o bálsamo democrático em comunhão com as normas presentes no seio social, as quais deverão dar o tom à resposta correta direcionada ao jurisdicionado, prezando pela unidade interpretativa do sistema jurídico.

Ou seja, nessa situação, Hércules deve sair da "torre de marfim"6 na qual fora catapultado por um conhecimento onisciente, buscando no diálogo social e plural, a participação dos cidadãos da esfera pública para a formação do discurso e as decisões judiciais democráticas (GÓES, 2013, p. 184).

Aliás, a produção da decisão e posteriormente do precedente judicial, obedece a outros critérios, até mesmo pela relevância política do Judiciário. Recairia em outra simplificação entender essa formação com bases tão somente jurídicas.

\footnotetext{
${ }^{5}$ No afã de aprofundar na teoria de Jürgen Habermas, eis a obra de Álvaro Cruz (2008).

${ }^{6}$ Expressão designada por Ricardo Tinoco de Góes, em sua obra "Democracia Deliberativa e Jurisdição: a legitimidade da decisão judicial a partir e para além da teoria de J. Habermas”.
} 
Com efeito, aquelas perspectivas morais e principiológicas são inerentes ao conceito de Direito, mesmo que não estejam previstas na norma, devendo igualmente orientar o trabalho de decidir judicialmente (MAUS, 2000, p. 186). Na aproximação entre Direito e Moral, a interpretação judicial passou a ser guiada não mais pela discricionariedade do magistrado, mas, sim, pelos julgamentos anteriormente proferidos. De todo modo, o direito não pode ser a leitura do que os tribunais dizem ser (STRECK, 2013, p. 344), pela perspectiva da autoridade interpretativa.

Nesse ponto, Ronald Dworkin expõe as bases da construção de uma decisão judicial, o que seria denominado como o "Romance em Cadeia", ora analisado sob a visão precedentalista, haja vista um precedente ter sua origem em um ato decisório. Em outras palavras, o magistrado deve ler o que fora desenvolvido pelos outros juízes e elaborar uma opinião particular sobre a obra coletiva produzida até então, determinando pelas suas próprias razões o motivo dos julgamentos anteriores (DWORKIN, 2019, p. 238). Desse modo, o dever do magistrado é interpretar a história jurídica que encontra, não inventar uma que julgue ser melhor. Todavia, não existe algoritmo para decidir se uma determinada interpretação é mais satisfatória à narrativa decisória (DWORKIN, 2019, p. 240).

Essa teoria dworkiana está atrelada ao princípio da integridade nas deliberações judiciais, a qual pode ser assimilada como a interligação a partir do viés literário e, por sua vez, com o respeito ao mundo vivido e à realidade. Afinal, todo este entrelaço deve convidar ao magistrado para assumir a sua responsabilidade enquanto julgador: a de reconhecer o seu papel na exegese judicial dos precedentes.

Para tanto, os magistrados precisariam tratar o sistema normativo como se esse fosse o resultado inicial de um conjunto coerente de princípios, interpretando esta esquematização no afã de encontrar normas implícitas entre o texto positivado (DWORKIN, 2014, p. 261). E aqui está a atitude principal do juiz que se pretende formador do romance.

Assim, vê-se que quando os juízes examinam e decidem casos no tradicional sistema precedentalista do common law, isto é, quando não há lei ocupando posição central na análise jurídica e o fundamento está pautado em princípios ou em outras regras, subentende-se que as decisões outrora proferidas, sobre casos semelhantes, hão de ser trazidas à luz. Cada juiz é como um autor romancista na corrente (DWORKIN, 2019, p. 238), o qual deverá enveredar pelo caminho já trilhado pelos seus predecessores.

Nesse sentido, transpondo para o cenário jurídico brasileiro, há uma tendência em colocar o magistrado de primeiro grau como mero aplicador do precedente interpretado pela Corte Superior. Não deveria existir espaço para tanto: é basilar a comunhão entre interpretar e aplicar a lei, mesmo na contramão do que preleciona a doutrina majoritária brasileira, consoante mencionado.

Dessa forma, na medida em que o direito brasileiro invoca o sistema precedentalista por uma mera previsão legal, determinando rol de mecanismos nascidos vinculantes (e não construídos, como deveria ser), acaba por restringir a atuação do juízo a quo vinculando-os à Corte de Vértices. Uma conclusão é certa: nenhum magistrado deve ser subordinado em absoluto à lei, tampouco ao precedente, mas em função da prestação jurisdicional, deve ter a responsabilidade de assegurar uma qualidade interpretativa respaldada em ambos.

Essa espécie de baliza hermenêutica precisa ser observada por todos os magistrados componentes do Poder Judiciário. Porém, parece óbvio que a construção do neo sistema de precedentes à brasileira incentiva que as Cortes Superiores descumpram com a exigência normativa da integridade no Direito. Como se os entendimentos construídos por essas Cortes invariavelmente não fossem igualmente fundados pelas instâncias inferiores, mesmo que por percepções contrapostas (STRECK, 2019, p. 78).

A Corte Superior, sobretudo o Supremo Tribunal Federal, deveria ser responsável não pela definição de conteúdo, mas por gerir o que já fora decidido. Ou seja, ao invés de funcionar

RAMOS, Raissa Holanda; DE GÓES, Ricardo Tinoco. PRECEDENTES JUDICIAIS À BRASILEIRA E O PÓS-POSITIVISMO: ANÁLISE DWORKIANA NA ATUAL FORMAÇÃO PRECEDENTALISTA. Revista Acadêmica da Faculdade de Direito do Recife - ISSN: 2448-2307, v. 93, n.1, p.338-349 Abr. 2021. ISSN 2448-2307. <Disponível em: 
como órgão limitador do precedente judicial, poderia assumir o papel de organizar e estabilizar o entendimento que é discutido nas instâncias inferiores. Portanto, quando a Corte firmasse uma posição, significaria que os debates substanciais foram discutidos na base, não podendo ser entendidas como um legislador concorrente ou um Poder Constituinte Originário anômalo (CRUZ, 2008, p. 200).

Não se pode olvidar que a aplicação do direito no Brasil, diante da ausência de uma teoria razoavelmente desenvolvida dos precedentes e do direito jurisprudencial em si, distancia-se do sistema íntegro, estável e coerente, pretendido pelo legislador processual. De fato, há uma adoção precipitada da teoria discutida, ensejando a sensação de que cada magistrado pode se distanciar das decisões pretéritas, o que resulta na ausência de previsibilidade da resposta do Poder Judiciário (HORTA; NUNES; PEDRON, 2017, p. 326). Por isso, os precedentes judiciais acabam por se configurar enquanto slogan da segurança jurídica, destacando-a como protagonista e valor maior do sistema jurídico a ser alcançado e implementado.

Por seu turno, na análise dworkiana, o juiz deve interpretar o que tiver acontecido no momento passado, haja vista a sua responsabilidade de levar adiante, em um aspecto prospectivo, a sua incumbência, continuando o labor decisório outrora encaminhado e não partir de uma nova direção interpretativa.

Pela previsão do Código de Processo Civil de 2015, especificamente em seus artigos 926 e seguintes, esta integridade interpretativa entre os magistrados ao longo da construção cronológica de uma decisão deverá seguir a coerência de casos semelhantes dessa mesma forma, porém sob outra nomenclatura, dada a incorporação legislativa dos precedentes judiciais. $\mathrm{Ou}$ seja, como aplicar essa integridade dworkiana às decisões judiciais que acarretarão precedentes judiciais? $\mathrm{Na}$ verdade, os precedentes judiciais brasileiros não obedecem a esta ordem necessariamente: primeiro uma decisão, depois um precedente passa a ser consolidado.

Em vista disso, não há a compreensão de que a integridade pretendida seja sinônimo de replicar a mesma decisão em casos factualmente similares. Na prática, significa estender aos precedentes uma restrita dinamicidade, incentivando ao magistrado transpassar da linha jurisprudencial exposta, do precedente hermeticamente analisado ou do texto expresso da súmula. Mais a mais, não se pode encará-los como o ponto final da argumentação, autorizando uma reprodução mecânica de decisões prolatadas no passado (LOPES FILHO, 2017, p. 164).

Essa integridade assevera por normas públicas construídas pela comunidade e que sejam vistas, de modo a expressar um sistema único, coerente e criado pela história da sociedade. $\mathrm{O}$ juiz não pode se manter inerte a tanto para decidir.

Ademais, atente-se: a integridade dos precedentes judiciais é diferente daquela esperada pelas leis. Portanto, estar-se-ia diante de outro argumento para balizar a impossibilidade de o legislador brasileiro ter albergado a teoria precedentalista pela via legislativa, enquadrando um instituto de acordo com as nuances da tradição jurídica nacional.

A integridade precedentalista pressupõe harmonia com outros elementos - sobretudo principiológicos - do sistema jurídico. Em contraposição a isso, eis o positivismo das leis, as quais guardam relação com a sua reprodução e uma estrutura formal, restrita e reduzida.

Segundo Ronald Dworkin (2014, p. 273), a ciência jurídica em si é formada por direitos e deveres, mas não apenas. Somem-se as decisões coletivas, judiciais ou não, em cujo teor está o conteúdo explícito e o sistema de princípios que justifica essas decisões: aqui estará a integridade pretendida.

Assim, mesmo quando o direito brasileiro busca em Dworkin as ideias de integridade do ordenamento e a construção da decisão judicial por uma verdade revelada pelas tradições e práticas sociais, é imperioso que essa influência seja realizada levando em consideração a historicidade constitutiva da sociedade propriamente dita, notoriamente distinta daquela que preponderou nos estudos do jurista e no surgimento da teoria dos precedentes judiciais.

RAMOS, Raissa Holanda; DE GÓES, Ricardo Tinoco. PRECEDENTES JUDICIAIS À BRASILEIRA E O PÓS-POSITIVISMO: ANÁLISE DWORKIANA NA ATUAL FORMAÇÃO PRECEDENTALISTA. Revista Acadêmica da Faculdade de Direito do Recife ISSN: 2448-2307, v. 93, n.1, p.338-349 Ab 


\section{CONCLUSÃO}

À guisa de conclusão, o presente trabalho propôs-se a evidenciar a fragilidade do sistema de precedentes judiciais à brasileira, o qual pretendeu construir o legislador, mediante uma simplória incorporação do instituto pela via legislativa ordinária. A falta de uma reflexão acerca da teoria precedentalista para além da aceitação acrítica de todos os termos propostos no Código de Processo Civil de 2015, vem causando uma concentração nas Cortes Superiores da formação dos precedentes judiciais e, por consequência, da construção de todas as decisões vinculantes no Brasil.

A despeito de se reconhecer a importância de a legislação processual determinar uma rede normativa estável, íntegra e coerente, sobretudo com as bases teóricas em Ronald Dworkin, a formação dos precedentes judiciais não pode ocorrer de qualquer forma, tão somente em decorrência de uma estimativa legal.

Em suma, entende-se que o positivismo jurídico, nada obstante, presente nos sistemas normativos mais tradicionais, não pode servir como limitante e reducionista do precedente judicial a ser formulado, mesmo que mediante uma pretensão voltada a revesti-los de nuances e particularidades contidas no direito brasileiro.

\section{REFERÊNCIAS}

BAHIA, Charles Nunes.As críticas de Dworkin levaram a uma superação do legado de Hart?Revista Eletrônica da Faculdade de Direito de Franca, São Paulo, v. 14, n. 2, dez. 2019. Disponível em: https://www.revista.direitofranca.br/index.php/refdf/article/view/715. Acesso em: 20 jan. 2020.

BOBBIO, Norberto. Teoria da norma jurídica. 6. ed. São Paulo: Edipro, 2016.

BRASIL. Lei Federal n ${ }^{\circ}$ 13.105, de 16 de março de 2015. Código de Processo Civil. Diário Oficial da União.Disponível em: http://www.planalto.gov.br/ccivil_03/_ato20152018/2015/lei/113105.htm. Acesso em: 19 abr. 2020.

CRUZ, Álvaro Ricardo de Souza. Habermas e o direito brasileiro.Rio de Janeiro: Lumen Juris, 2008.

DIMOULIS, Dimitri. A relevância prática do positivismo jurídico. Revista Brasileira de Estudos Políticos, Minas Gerais, n. 102, jun. 2011. Disponível em: https://pos.direito.ufmg.br/rbep/index.php/rbep/article/view/132. Acessoem: 15 jan. 2020.

DWORKIN, Ronald. Law as interpretation.Texas Law Review, v. 60, p. 527-550, 1982.

DWORKIN, Ronald. Levando os direitos a sério. 3. ed. São Paulo: Martins Fontes, 2010.

DWORKIN, Ronald. O império do direito. 3. ed. Martins Fontes: São Paulo, 2014.

DWORKIN, Ronald. Uma questão de princípio. 3. ed. São Paulo: Martins Fontes, 2019.

GOES, Ricardo Tinoco. Democracia deliberativa e jurisdição: a legitimidade da decisãojudicial a partir e para além da teoria de J. Habermas. Curitiba: Juruá, 2013. 
HORTA, André Frederico de Sena; NUNES, Dierle; PEDRON, Flávio Quinaud. Art. 926 do CPC e suas propostas de fundamentação: um diálogo com concepções contrastantes. In: JAYME, Fernando Gonzaga; MENDES, Aluisio; NUNES, Dierle (org.). A nova aplicação da jurisprudência e precedentes no CPC/2015. 1. ed. São Paulo: Revista dos Tribunais, 2017, p. 335-396.v. 263.

LEGALE, Siddharta. Superprecedentes. Revista Direito GV, São Paulo, v. 12, n. 3, set./dez. 2016. Disponível em:http://bibliotecadigital.fgv.br/ojs/index.php/revdireitogv/issue/view/3721. Acesso em: 20 abr. 2020.

LOPES FILHO, Juraci Mourão. Sistematização de precedentes e ordenamento jurídico: proposta de um paradigma teórico. Revista de Direito Brasileira, Santa Catarina, v. 18, n.7, dez. 2017. Disponível em: https://www.indexlaw.org/index.php/rdb/article/view/3112. Acesso em: 20 jan. 2020 .

LUIZ, Fernando VIEIRA. Por que tenho medo do "sistema de precedentes" do CPC/15: a aplicação do direito jurisprudencial à luz do direito como integridade de Ronald Dworkin. 669f. Tese (Doutorado em Direito) - Universidade Federal de Santa Catarina, Florianópolis, 2018. Disponível em: https://repositorio.ufsc.br/handle/123456789/198453. Acesso em: 15 jan. 2020.

MAUS, Ingerborg. Judiciário como superego da sociedade. O papel da atividade jurisprudencial na "sociedade órfă". Tradução de Martonio Lima e Paulo Albuquerque. Novos Estudos, n. 58, nov. 2000.

MOREIRA, Nelson Camatta; SILVA, Tatiana Mareto. Análise crítica do positivismo jurídico em face dos direitos humanos na perspectiva do filme "O julgamento de Nuremberg". Revista Derecho y Cambio Social,Lima, Peru, n. 44, ano 13, 2016. Disponível em: https://www.derechoycambiosocial.com/revista044/INDICE_POR.htm. Acesso em: 18 abr. 2020.

PEIXOTO, Ravi. Superação do precedente e segurança jurídica.4. ed. Salvador: Juspodium, 2019.

SAAVEDRA, Giovani Agostini. Jurisdição e democracia: uma análise a partir das teorias de Jurgen Habermas, Robert Alexy, Ronald Dworkin e NiklasLuhmann. Porto Alegre: Livraria do Advogado, 2006.

STRECK, Lenio Luiz. Compreender direito. Desvelando as obviedades do discurso jurídico. 1. ed. São Paulo: Revista dos Tribunais, 2013.

TRECK, Lenio Luiz. Hermenêutica, constituição e autonomia do Direito. Revista de Estudos Constitucionais, Hermenêutica e Teoria do Direito (RECHTD), Rio Grande do Sul, v. 1, n. 1, jun. 2009. Disponível em: http://revistas.unisinos.br/index.php/RECHTD/article/view/5137. Acesso em: 17 jan. 2020.

TRECK, Lenio Luiz. O (pós-) positivismo e os propalados modelos de juiz (Hércules, Júpiter e Hermes) - dois decálogos necessários. Revista de Direitos e Garantias Fundamentais, Espírito Santo, n. 7, jun. 2010. Disponível em: http://www.direitocontemporaneo.com/wpcontent/uploads/2014/02/O-PÓS-POSITIVISMO-E-OS-PROPALADOS-MODELOS-DE-JUIZHÉRCULES-JÚPITER-E-HERMES---DOIS-DECÁLOGOS-NECESSÁRIOS.pdf. Acesso em: 17 jan. 2020. 
TRECK, Lenio Luiz. Porque a discricionariedade é um grave problema para Dworkin e não é para Alexy. Revista Direito e Práxis, v. 4, n. 7, 2013. Disponível em: https://www.epublicacoes.uerj.br/index.php/revistaceaju/issue/view/617. Acesso em: 16 jan. 2020.

TRECK, Lenio Luiz. Precedentes judiciais e hermenêutica. O sentido da vinculação no CPC/2015. 2. ed.Salvador: Juspodium, 2019. 